\title{
Comparison of Molecular and Morphological Identification of Ticks in Vellore District of Tamil Nadu
}

\section{Kalaimani Saravanan}

Thiruvalluvar University

\section{Rajasekar Aruliah}

Thiruvalluvar University

John A J Prakash

Christian Medical College

Kamarasu Kannan

Institute of Vector Control and Zoonoses

\section{Ramlingam Paramasivan}

Institute of Vector Control and Zoonoses

Ernest David ( $\nabla$ ernestdavid2009@gmail.com )

Thiruvalluvar University https://orcid.org/0000-0001-9865-5627

\section{Research Article}

Keywords: Rhipicephalus sp, Heamaphisalis sp, Hylomma marginatum, Vellore, Tamil Nadu

Posted Date: January 21st, 2022

DOI: https://doi.org/10.21203/rs.3.rs-1253007/v1

License: (1) This work is licensed under a Creative Commons Attribution 4.0 International License. Read Full License 


\section{Abstract}

In this study, we have comparatively identified molecular and morphological features of ticks in Vellore district of Tamil Nadu. A total of 541 ticks were collected from domestic animals in the Vellore district of Tamil Nadu. The research was carried out between October 2018 and December 2019. The collected tick specimens were transferred into two sterile tubes and stored at room temperature in $70 \%$ alcohol. The tick was identified using PCR amplification of the 18SrRNA genes of Rhipicephalus sp (MW131877, MW318996, MW131878, MT952071) and Heamaphysalis sp (MW327046), the mtCOX1 gene of Rhipicephalus microplus (MT941478, MT941466, MT941463), and Hylomma marginatum (MW327046) (MW322564). The phylogenetic tree indicates that there was a common ancestor tick between Rhipicephalus sp., Heamaphysalis sp., and Hylomma marginatum in Vellore, Tamil Nadu. The tick was identified morphologically as two genera, Rhipicephalus $s p$. and Heamaphysalis $s p$. This is one of the first reports on ticks in the Vellore district of Tamil Nadu, as well as the morphological confirmation of two genera, Rhipicephalus and Heamaphisalis, through the sequencing of the 18SrRNA and mtCOX1 genes.

\section{Introduction}

Ticks are a hematophagous ectoparasites which are living through feeding on the blood of their vertebrate hosts, mammals, and some other amphibians and reptiles. Generally, ticks are nonsegmented body whereas it has four sets of legs in adults and three sets of legs in their larval stage [1,2]. Ticks can be red, brown, or black. They range from around .5 to $3.0 \mathrm{~mm}$ in length. After feeding, the ticks may expand to $11 \mathrm{~mm}$. Adult ticks have pear-shaped bodies (idiosomas) which become engorged with blood when they feed, and eight legs. Ticks (Acari: Ixodidae) are an animal parasitic spider species classified into three major families such as Ixodidae (hard ticks), Nuttalliellidae and Argasidae (soft ticks). Each of these three families has survived individual and biological. Commonly, ticks are locating on the potential host organism by sensing odor, moisture, body heat, and some other vibrations in the environment [3]. Ixodidae or hard ticks have a thick dorsal scutum whereas Argasidae or soft ticks do not have any scutum. The body of male hard ticks covering by scutum thus it can ingest small quantities of blood from host. Ixodids are belonging to a major family of ticks species which spread myriad infections globally in veterinary and also contributes to the causes of some diseases in humans. Argasidea ticks have upto seven nymphal stages (instars), each stage of these seven requiring blood ingestions. Argasid ticks undergo a multihost lifestyle because of their hematophagous (blood-ingesting) diets [4]. Hard ticks have a feeding structure in front of their heads, whereas soft ticks have a very small and barely visible feeding structure on the underside of their body. The feeding structure of Ixodes ticks is larger than that of other hard ticks. Ticks go through several stages of development, including eggs, larvae, nymphs, and adults. To induce moulting, blood must be consumed between each stage. Ticks are thus hematophagous at all stages of development. The egg is the first stage in the life cycle of a tick. At this stage, hard ticks lay hundreds or even thousands of eggs all at once, whereas soft ticks lay eggs in batches of 20 to 100 over a long period of time $[5,6]$. The larvae are secondary, the tick larvae have 3 
pairs of legs. Larval stage varies from 3 to 13 days. Another condition followed by nymphs' larvae is that the nymphs all suck blood and attach to hosts suitable for blood feeding. Ticks in adulthood survive a year or more. Soft ticks live longer than hard ticks. Female feeders usually require blood feeding for egg production. Although many tick bites are harmless, they can cause diseases in some humans. Tick bite symptoms include speech problem, sleep disorder, muscle aches, joint and neck pain and fatigue. Smith and Kilbourne discovered in 1893 the role of Boophilus annulatus as the vector of the protozoal causative agent Babesia bigemina for Texas veterinary flu, the first arthropods tick to be clearly established as vectors of infection $[7,8]$.

In 1903, when J.E Dutton, who worked in the Congo, discovered the main cause of local recurrent fever, ticks were first proven to be the vectors of human disease [9]. Tick-borne diseases of humans are usually characterized by other unspecified signs of acute zone infection such as cold, sweating, headache, muscle aches, arthralgias, fatigue, loss of appetite, nausea and vomiting. Tick-borne diseases thus cover without causing direct damage to animals, reducing the direct quality of weights and being one of the major barriers to livestock production in developing countries; milk production [10]. The occurrence and distribution of ixodid carnivores on various biotopes of sheep in Karnataka and various parts of South India were studied [11]. Kerala was reported in human infesting ixodid ticks [12,13]. Studies by tick activity revealed the most common tick species in Tamil Nadu with small ticks and moderate tick loads on Haemaphysalis bispinosa. Approximately, 106 Ixodid tick and Argasid tick species affect domestic, wild and game animals from India. Although the most recent studies mainly focused on specific geographical areas or livestock aspects [14]. This investigation proposes a connection between ticks having a place with the Rhipicephalus microplus. bunch and the topographical dispersion of Haemaphysalis sp and Hylomma margintum. Notwithstanding, the role of every agent tick species inside the Rhipicephalus microplus bunch in the transmission of these canine microorganisms should be additionally explored.

\section{Material And Methods}

\section{Specimen collection and identification}

From October 2018 to December 2019, 541 ticks were collected from domestic animals at four localities in the Vellore district in Tamil Nadu (Fig. 1). The collected samples were replaced the sterile tubes and preserved in $70 \%$ alcohol at room temperature. All the ticks were first identified morphologically with a stereomicroscope and then verified by molecular analyses. The tick was sent for morphological identification to IVCZ (Institute of Vector Control and Zoonoses) Hosur, Tamil Nadu. Three ticks were stained with Acetic-alum carmine (aqueous stain) overnight. They were washed in distilled water and then dehydrated in ascending grades of alcohol 30\%, 50\%, 70\% for 5 min each and $90 \%, 100 \%$ for 10 minutes each. After dehydration, the ticks were dipped in clearing agent Xylene. The ticks were mounted using DPX (Dextrin Plasticized Xylene). After applying a coverslip tick was observed under the NikonE200(Nikon, Tokyo, Japan) microscope. The ticks were identified to genus Rhipicephalus and 
Haemaphysalis using morphological key described by Roy and Brown and Haemaphysalis Ticks of India book by A C Mishra and G Geevarghese [15, 16].

\section{Nucleic Acid Extraction From Ticks}

DNA was extracted from a morphologically similar tick (Qiamp DNA blood and tissue mini kit, Qiagen, Hilden, Germany) according to the manufacturer's protocol. Tick was homogenised in $200 \mu$ ATL buffer using a mortar and pestle. It was then treated with a $20 \mu \mathrm{l}$ solution of Proteinase $\mathrm{K}$, followed by an overnight incubation at $56^{\circ} \mathrm{C}$. The following steps were carried out in accordance with the manufacturer's instructions. The final elute $(100 \mu \mathrm{l})$ was kept at $-20^{\circ} \mathrm{C}$ until the PCR amplification.

\section{Amplification Of Target Genes}

Conventional PCR was used to amplify DNA fragments from four target genes. Table 1 lists the primers used to amplify the target genes. The QIAGEN Multiplex PCR Kit (Hilden, Germany) was used in this study. The reaction was carried out using a $50 \mu \mathrm{l}$ master mix volume and a $5 \mu$ template for $18 \mathrm{~S}$ rRNA, COI (772 \& 773) and LC01490 \& HCO2198, COI (COX1F \& COX1R) gene, as described in [17, 18, 19, 20]. Each reaction used a primer concentration of $20 \mathrm{pmol}$. In a Veritithermal cycler, all targets were amplified (Applied biosystem, Foster City, CA, USA). Table 2 displays the thermal cycling parameters. PCR products were subjected to 2 percent $(\mathrm{w} / \mathrm{v})$ agarose gel electrophoresis containing ethidium bromide to determine correct product sizes. with $100 \mathrm{~kb}$ plus ladder A UV Transilluminator (Bio-Rad, Gel doc XR+, USA) was used to view the gel.

Table 1

Primers used for amplification of 18S rRNA and COI from ticks

\begin{tabular}{|c|c|c|c|c|}
\hline Gene & Primer & Oligo Sequence (5'-3') & $\begin{array}{l}\text { Amplicon } \\
\text { Size }\end{array}$ & References \\
\hline \multirow{2}{*}{$\begin{array}{l}18 \mathrm{~S} \\
\text { rRNA }\end{array}$} & NSF4/18 & CTGGTTGATYCTGCCAGT & \multirow[t]{2}{*}{$400 b p$} & \multirow[t]{2}{*}{ Duron O (2008) } \\
\hline & NSR399/19 & TCTCAGGCTCCYTCTCCGG & & \\
\hline \multirow[t]{2}{*}{$\mathrm{COI}$} & 772 & TGATTTTTTGGTCACCCAGAAG & \multirow[t]{2}{*}{$334 b p$} & \multirow{2}{*}{$\begin{array}{l}\text { Jacinavicius FC } \\
(2018)\end{array}$} \\
\hline & 773 & TACAGCTCCTATAGATAAAAC & & \\
\hline \multirow[t]{2}{*}{$\mathrm{COI}$} & LC01490 & GGTCAACAAATCATAAAGATATTGG & \multirow[t]{2}{*}{$680 \mathrm{bp}$} & \multirow[t]{2}{*}{ Folmer O (1994) } \\
\hline & HCO2198 & TAAACTTCAGGGTGACCAAAAAATCA & & \\
\hline \multirow[t]{2}{*}{$\mathrm{COI}$} & Cox1F & GGAACAATATATTTAATTTTTGG & \multirow[t]{2}{*}{ 820bp } & \multirow{2}{*}{$\begin{array}{l}\text { Chitimia et al., } \\
2010\end{array}$} \\
\hline & Cox1R & ATCTATCCCTACTGTAAATATATG & & \\
\hline
\end{tabular}


Table 2

Cycling condition for conventional PCR Target

\begin{tabular}{|c|c|c|c|c|c|}
\hline Target & $\begin{array}{l}\text { Initial } \\
\text { denaturation }\end{array}$ & $\begin{array}{l}\text { Denaturation } \\
\text { Temperature }\end{array}$ & $\begin{array}{l}\text { Annealing } \\
\text { temperature }\end{array}$ & Extension & Cycles \\
\hline 18S rRNA & $\begin{array}{l}95^{\circ} \mathrm{C} \text { for } 2 \\
\min \end{array}$ & $\begin{array}{l}94^{\circ} \mathrm{C} \text { for } 30 \\
\mathrm{sec}\end{array}$ & $\begin{array}{l}55^{\circ} \mathrm{C} \text { for } 30 \\
\mathrm{sec}\end{array}$ & $\begin{array}{l}72^{\circ} \mathrm{C} \text { for } 1 \\
\min \end{array}$ & 40 \\
\hline $\begin{array}{l}\text { COI (772 \& 773) \& } \\
(\text { LCO1490 } \\
\& H C O 2198)\end{array}$ & $\begin{array}{l}95^{\circ} \mathrm{C} \text { for } 4 \\
\min \end{array}$ & $\begin{array}{l}95^{\circ} \mathrm{C} \text { for } 60 \\
\mathrm{sec}\end{array}$ & $\begin{array}{l}50^{\circ} \mathrm{C} \text { for } 60 \\
\mathrm{sec}\end{array}$ & $\begin{array}{l}72^{\circ} \mathrm{C} \text { for } 1 \\
\min \end{array}$ & 40 \\
\hline $\begin{array}{l}\text { COl (Cox1F \& } \\
\text { Cox1R) }\end{array}$ & $\begin{array}{l}94^{\circ} \mathrm{C} \text { for } 5 \\
\min \end{array}$ & $\begin{array}{l}94^{\circ} \mathrm{C} \text { for } 60 \\
\mathrm{sec}\end{array}$ & $\begin{array}{l}45^{\circ} \mathrm{C} \text { for } 30 \\
\mathrm{sec}\end{array}$ & $\begin{array}{l}72^{\circ} \mathrm{C} \text { for } \\
60 \mathrm{sec}\end{array}$ & 40 \\
\hline
\end{tabular}

\section{Gene Sequencing And Phylogenetic Analysis}

The PCR products were purified according to the manufacturer's instructions using a QIAquick DNA purification kit (Qiagen, Hilden, Germany). Purified PCR products were sequenced in both directions with the Big Dye Terminator Cycle Sequencing Kit v 3.1 (Applied Biosystems, CA, USA), and the sequences were analysed using capillary electrophoresis in the ABI Prism 3100 Genetic Analyzer (Applied systems). Finch TV was used to edit the chromatogram. The sequences were merged online using the EMBOSS merger tool (https://www.bioinformatics.nl/cgi-bin/emboss/merger), and homology was determined using the GenBank BLAST tool (Basic Local Alignment Search Tool). MEGA7 was used to align nucleotide sequences from the 18SrRNA and COI gene sequences obtained in this study with sequences downloaded from the NCBI GenBank database. The maximum likelihood method was used to estimate and select the best-fit substitution model. Out-groups for 18SrRNA and COI were Rhipicephalus sp., Haemaphysalis sp., and Hyalomma margintum, respectively (Figure 3 and 4).

\section{Results And Discussion}

The present study was conducted to determine the prevalence of hard tick infections in domestic animals of Vellore district Tamil Nadu from October 2018 to December 2019. We have collected 541 tick samples ( 50 from this study 9 from Gen bank) nine species and two genera of the hard tick. The mitochondrial COI region of samples were collected in Vellore district. We successfully amplified gene sequence using PCR. COI gene, Rhipicephalus microplus, Hylomma margintum 18SrRNA, Rhipicephalus sp, Haemaphasalis sp. The belongs to the genus of hard tick (Ixodida). Among these, three different species were identified. Of them, Rhipicephalus sp, Haemaphasalis sp. Hylomma sp from 18SrRNA, two different species were identified in Rhipicephalus microplus, Hylomma margintum from the Cytochrome oxidase 1(COI) gene. 
Ticks have long been recognised for their medical and veterinary value. The dispersion and availability of tick species that infest cattle varies greatly by region. The current study investigates the prevalence of tick infestations in a domestic animal from Vellore. Infections with Rhipicephalus (Boophilus) sp., Hyalomma $s p$., and Haemaphysalis sp., as well as mixed infections, were found to be 32.25 percent, 12.58 percent, 3.22 percent, and 6.12 percent, respectively [21]. This study's findings were consistent with previous reports from various parts of India and abroad [22, 23, 24].

A reliable database is the foundation of barcodes, with rows formed from expertly identified and confirmed models. This database contains rows of published and supported feeders in the BOLD system. Furthermore, studies on tick phylogeny provide a high level of reliability for $\mathrm{COI}, 16 \mathrm{~S}$, and $18 \mathrm{~S}$ sequences because these sequences originated from models identified by tick experts [25]. Because COI is used to identify birds, fish, and arthropods, it is believed that this gene can provide better resolution to the predator on the scale; however, the number of COI sequences published at BOLD and GenBank is 325 from 66 species, which is insufficient to establish a DNA barcoding system. To complete the COI, it is best to add more genetic sites to the DNA barcoding system. $16 \mathrm{~S}$ is a popular marker for determining tick evolution and biogenetic relationships. To date, the number of ticks in the $16 \mathrm{~S}$ released at GenBank exceeds the $\mathrm{COI}$ by more than twofold, totalling 647 out of 129 species. According to our findings, they are effective at tick discrimination at the COI and 16S species levels [26].

Previous research has shown that $18 \mathrm{~S}$ is generally protected. However, the full length of the $18 \mathrm{~S}$ is 1800 $\mathrm{bp}$, which exceeds the upper limit for DNA barcode length. Considering the length of universal primers and PCR products for the $18 \mathrm{~S}$, a fraction of $780 \mathrm{bp}$ was studied. In addition, the neighbor joining tree dependent on $18 \mathrm{~S}$ gave critical topological goal at the genera level, and this outcome was not totally predictable with past information. Possible explanations include a fragment of $780 \mathrm{bp}$, but the full length of the $18 \mathrm{~S}$ has not been used in terms of $\mathrm{NJ}$ analysis; the phylogenetic tree was based on the NJ method but not on other bioinformatics methods [27].

Tick specimens collected from domestic animals were taxonomically classified into two genera, Rhipicephalus and Haemaphasalis, identified at the Institute of Vector Control and Zoonoses in Hosur (IVCZ). The two species mentioned above could be classified as a single family, Ixodidae. Miranpuri and Singh (1978) has reported ixodid ticks on domestic animals are common in several other Indian states, including Assam, Karnataka, and Tamil Nadu. [28, 29, 30].

Some of the Rhipicephalus species studied here (e.g., R. sanguineus s.I., R. sp. I, and R. sp. II) shared striking morphological similarities. However, morphological examination of the main characters (for example, female genital opening shape, male adenal plate shape, squat stop pattern, and spiral plate shape in both sexes) assisted us in distinguishing these species. Importantly, adult measurements are known to be ineffective for distinguishing Rhipicephalus species. However, given the differences found here for some specific characters (e.g., adanal plate length / width ratio), future research should better assess the utility of morphometric analysis in distinguishing between Rhipicephalus adults and immature conditions. Our genetic analyses confirmed the separation of all the Rhipicephaline species examined by 
supporting the presence of distinct clades. High genetic integration has been discovered within the $R$. microplus tick population, regardless of geographical appearance. It was also hypothesised based on intra- and interspecific nucleotide variations in mitochondrial DNA that clearly defined the molecular identities of Rhipicephalus sp., R.microplus, Haemaphysalis sp., and Hyalomma margintum.

Finally, the current study discusses the results of a survey on the species diversity of ixodid ticks infesting Vellore's domestic animals. Natural tick infestations have been observed on host animals such as cows, goats, dogs, and sheep. This demonstrates that tick infection is a significant impediment to the proper development and well-being of the important domestic animals in Tamil Nadu's Vellore district.

\section{Conclusion}

In this study, the most common arthropod vectors identified in the Vellore district of Tamil Nadu, India. Our study was successfully developed on Ixodida based on COI and 18S. Our data suggest that this DNA extraction successfully identifies Rhipicephalus microplus and Hyalomma margintum and Haemaphysalis species in adulthood. Our work provides a significant device and a generally helpful convention for tick distinguishing using molecular technology. were, and Hyalomma. PCR is more sensitive in detecting blood pathogens compared to microscopic blood test. Co-infections between pathogens are very common in domestic animals in India These warrants have increased awareness among veterinarians.

\section{Declarations}

\section{Acknowledgments}

The authors would like to express their gratitude to the Institutional Review Board of Christian Medical College, Vellore (83-i/11/13) for endorsing the study and offering lab facilities. Also, we thanks to the Institute Vector Control and Zoonoses, Hosur for the morphological identification of ticks.

\section{Compliance with ethical standards}

Conflict of interest: The authors declare that they have no conflict of interest.

Ethical approval: This study was duly approved by the Christian Medical College and Hospital, Vellore. Institutional Review Board (Reference Number: 9369).

\section{References}

1. Duvallet G, Boulanger N, Robert V Arthropods: definition and medical importance. InSkin and Arthropod Vectors 2018 Jan 1 (pp.29-54).Academic Press

2. Robert LL Jr, Debboun M Arthropods of Public Health Importance. InHunter's Tropical Medicine and Emerging Infectious Diseases 2020 Jan 1 (pp.1055-1062). Elsevier 
3. Kopsco HL, Mather TN Ecological Factors Influencing the Landscape Epidemiology of Tickborne Disease. InLandscape and Land Capacity 2020 May 19 (pp.329-343).CRC Press

4. Nicholson WL, Sonenshine DE, Noden BH, Brown RN Ticks (Ixodida). InMedical and veterinary entomology 2019 Jan 1 (pp.603-672).Academic Press

5. Boulanger $N$, Boyer $P$, Talagrand-Reboul E, Hansmann $Y$ (2019) Ticks and tick-borne diseases. Medecine et maladies infectieuses. Mar 1;49(2):87-97

6. Apanaskevich DA, Oliver JH, Sonenshine DE, Roe RM (2013) Life cycles and natural history of ticks. Biology of ticks 1:59-73

7. Smith T, Kilborne FL (1893) Investigations into nature, causation, and prevalence of Texas or southern cattle fever, vol 1-5. U.S.Department of Agriculture, Bureau of Animal Industry, Washington, D.C.

8. Balinandi S, Chitimia-Dobler L, Grandi G, Nakayiki T, Kabasa W, Bbira J, Lutwama JJ, Bakkes DK, Malmberg M, Mugisha L (2020 Aug) Morphological and molecular identification of ixodid tick species (Acari: Ixodidae) infesting cattle in Uganda. Parasitol Res 119(8):2411-2420

9. Dutton JE, Todd JL, Kinghorn A (1907) Cattle Trypanosomiasis in the Congo Free State: Being the Eighth Progress Report of the Expedition of the Liverpool School of Tropical Medicine to the Congo, 1903-05. Annals of Tropical Medicine \& Parasitology. Feb 1;1(1-5):232-74

10. Andersen NS, Bestehorn M, Chitimia-Dobler L, Kolmos HJ, Jensen PM, Dobler G, Skarphédinsson S Phylogenetic characterization of tick-borne encephalitis virus from Bornholm, Denmark. Ticks and tick-borne diseases. 2019 Apr 1;10(3):533-9

11. Ranganathan K, Govindarajan RE, Ayyanar E, Veeramanoharan R, Paulraj PS Species composition of hard ticks (Acari: Ixodidae) on domestic animals and their public health importance in Tamil Nadu, South India.Acarological Studies.; 3(1):16-21

12. Shyma KP, Stanley B, Ray DD, Ghosh S (2013) Prevalence of cattle and buffalo ticks in northern Kerala. Journal of Veterinary Parasitology 27(1):55-56

13. Jadhao (2018) sg, pal s, nath s, kumar s, sanyal pk. prevalence of hard ticks (acari: ixididae) of indian zebu cattle (kosli) in bastar plateu zone of chhattisgarh, india. J. Exp. Zool., India. ;21(2):83741

14. Kumar KA, Ravindran R, Johns J, Chandy G, Rajagopal K, Chandrasekhar L, George AJ, Ghosh S (2018 Sep) Ixodid tick vectors of wild mammals and reptiles of Southern India. Journal of Arthropodborne diseases. 12:2763

15. Geevarghese G, Mishra AC (2011 Jul) Haemaphysalis ticks of India. Elsevier, p 11

16. Roy DN, Brown AW (1970) Entomology (medical and veterinary). Bangalore Printing and Publishing, Bangalore, pp 429-437

17. Duron O, Bouchon D, Boutin S, Bellamy L, Zhou L, Engelstädter J, Hurst GD (2008 Dec) The diversity of reproductive parasites among arthropods: Wolbachia do not walk alone. BMC Biol 6(1):1-2 
18. Roy DN, Brown AW (1970) Entomology (medical and veterinary). Bangalore Printing and Publishing, Bangalore, pp 429-437

19. Folmer O, Black M, Hoeh W, Lutz R, Vrijenhoek R (1994) DNA primers for amplification of mitochondrial cytochrome c oxidase subunit I from diverse metazoan invertebrates. Mar Biotechnol(NY) 3(5):294-299

20. Lv J, Wu S, Zhang Y, Chen Y, Feng C, Yuan X, Jia G, Deng J, Wang C, Wang Q, Mei L (2014 Dec) Assessment of four DNA fragments (COI, 16S rDNA, ITS2, 12S rDNA) for species identification of the Ixodida (Acari: Ixodida). Parasites \& vectors 7(1):1-1

21. Debbarma A, Pandit S, Jas R, Baidya S, Mandal SC, Jana PS (2018) Prevalence of hard tick infestations in cattle of West Bengal, India. Biological Rhythm Research. Sep 3;49(5):655-62

22. Ghafar A, Gasser RB, Rashid I, Ghafoor A, Jabbar A (2020) Exploring the prevalence and diversity of bovine ticks in five agro-ecological zones of Pakistan using phenetic and genetic tools. Ticks and Tick-borne Diseases. Sep 1;11(5):101472

23. Patra G, Sahara A, Ghosh S, Behera P, Borthakur SK, Biswas P, Debbarma A, Sahanawaz Alam S (2020 Feb) Prevalence of tick-borne pathogens in domestic dogs in North-Eastern region of India. Biological Rhythm Research 17(2):184-193

24. Kumar N, Solanki JB, Varghese A, Jadav MM, Das B, Patel MD, Patel DC (2019 Dec) Molecular assessment of Anaplasma marginale in bovine and Rhipicephalus (Boophilus) microplus tick of endemic tribal belt of coastal South Gujarat, India. Acta parasitologica 64(4):700-709

25. Lv J, Wu S, Zhang Y, Chen Y, Feng C, Yuan X, Jia G, Deng J, Wang C, Wang Q, Mei L (2014 Dec) Assessment of four DNA fragments (COI, 16S rDNA, ITS2, 12S rDNA) for species identification of the Ixodida (Acari: Ixodida). Parasites \& vectors 7(1):1-1

26. Lv J, Wu S, Zhang Y, Zhang T, Feng C, Jia G, Lin X (2013) Development of a DNA barcoding system for the Ixodida (Acari: Ixodida). Mitochondrial DNA 25(2):142-149

27. Hadziavdic K, Lekang K, Lanzen A, Jonassen I, Thompson EM, Troedsson C (2014) Characterization of the $18 \mathrm{~S}$ rRNA gene for designing universal eukaryote specific primers. PloS one. Feb 7;9(2):e87624

28. Kumar K, Balakrishnan N, Sharma AK (2014) Jan Studies on the vertical distribution of ticks of domestic animals and their public health importance in Nilgiri Hills and adjoining areas of Tamil Nadu State (India).International Journal of Zoology. 1;2014.

29. Kakati P, Sarmah PC, Ray D, Bhattacharjee K, Sharma RK, Barkalita LM, Sarma DK, Baishya BC, Borah P, Stanley B (2015) Emergence of oriental theileriosis in cattle and its transmission through Rhipicephalus (Boophilus) microplus in Assam, India. Veterinary world. Sep;8(9):1099

30. Miranpuri GS, Singh J, Lahkar BC (1978) Host-relationship and distribution of ixodid ticks (Ixodoidea: Acarina) in the Assam valley [India].Indian Journal of Ecology.

\section{Figures}




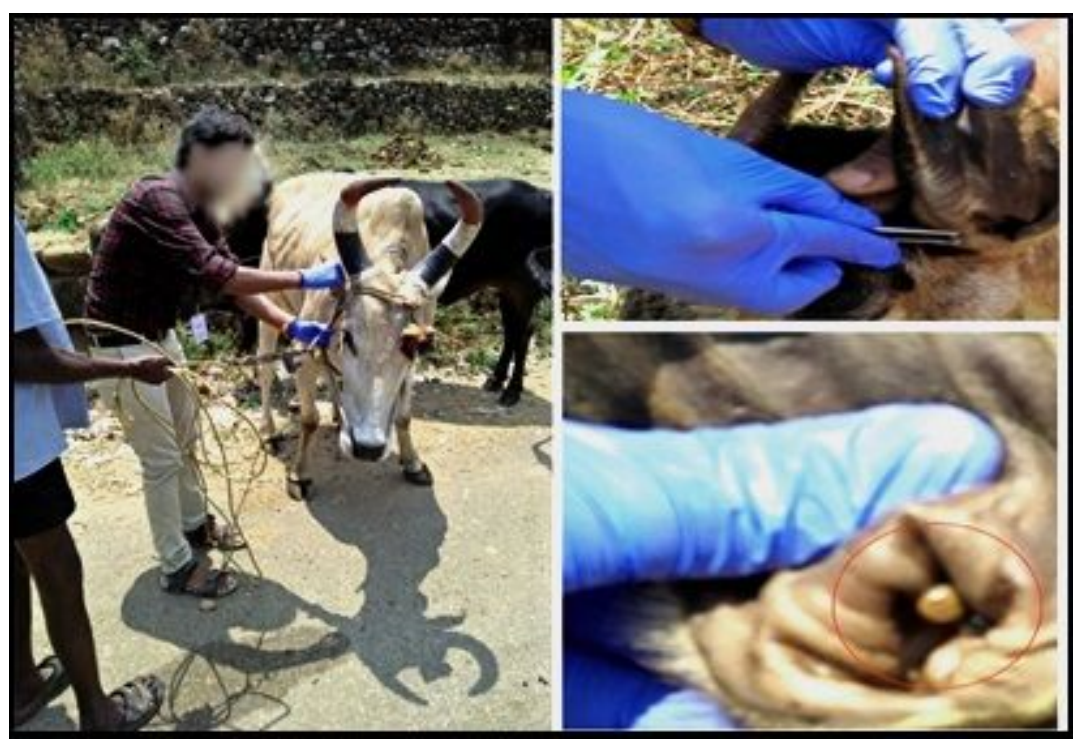

Figure 1

Tick specimen collection from domestic animals. 

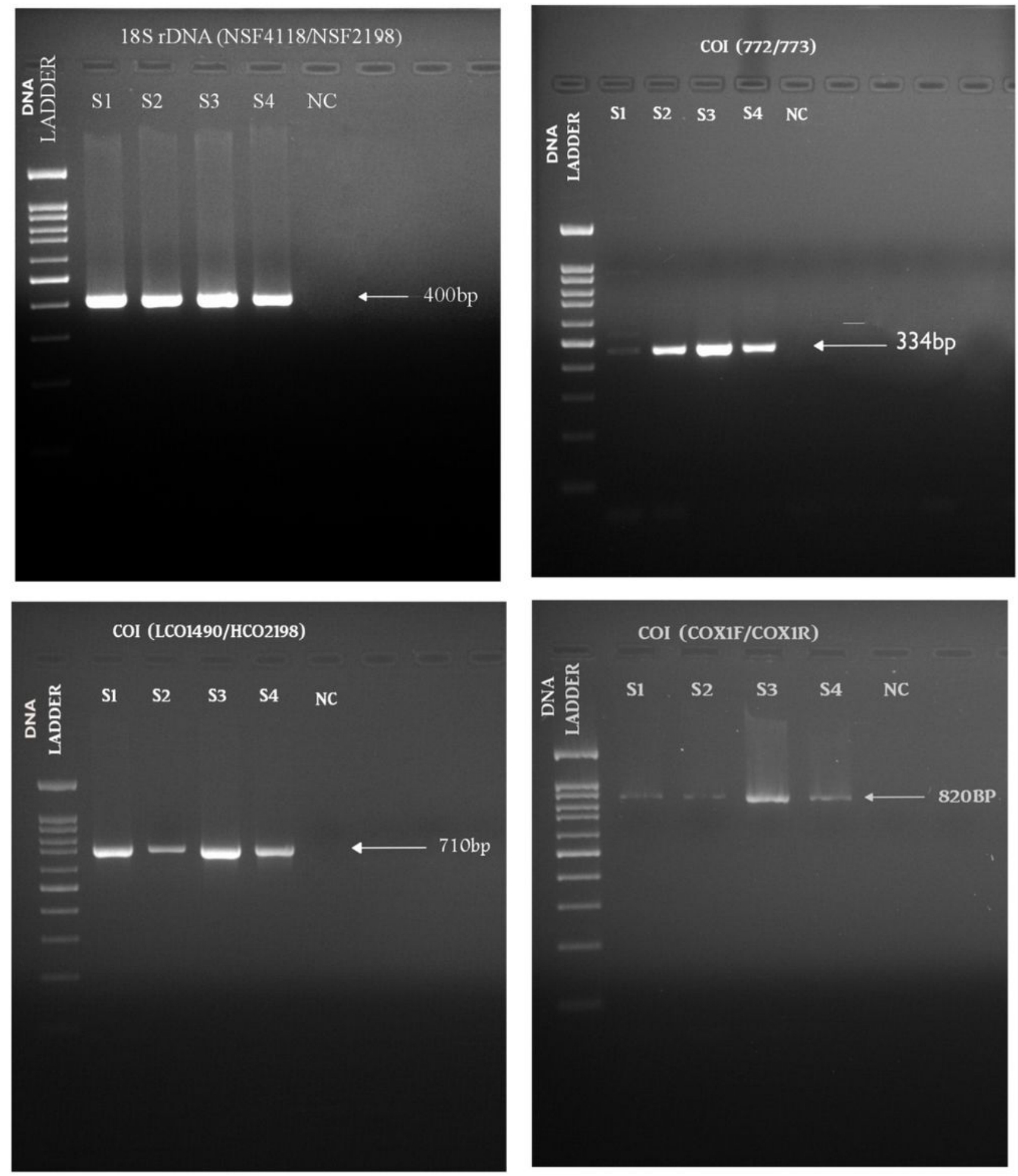

\section{Figure 2}

Agarose gel electrophoresis of PCR amplificons after amplification of 18SrRNA and COI gene-Specific DNA fragment from Tick DNA 


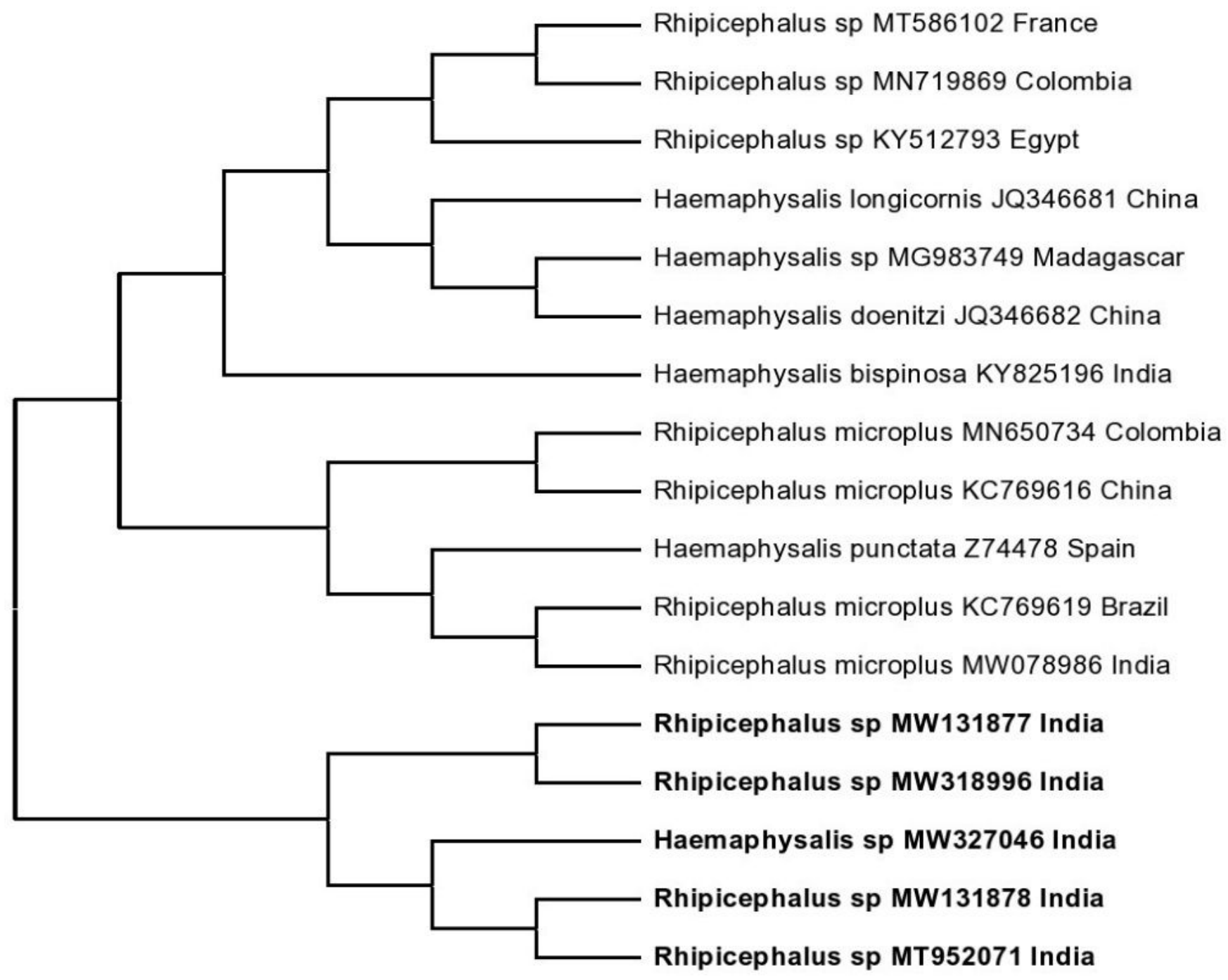

Figure 3

Molecular phylogenetic analysis of Rhipicephalus $s p$ and Haemaphysalis sp isolated from the tick. 18S rRNA was concatenated and subjected to analysis by the neighbor-joining method. 


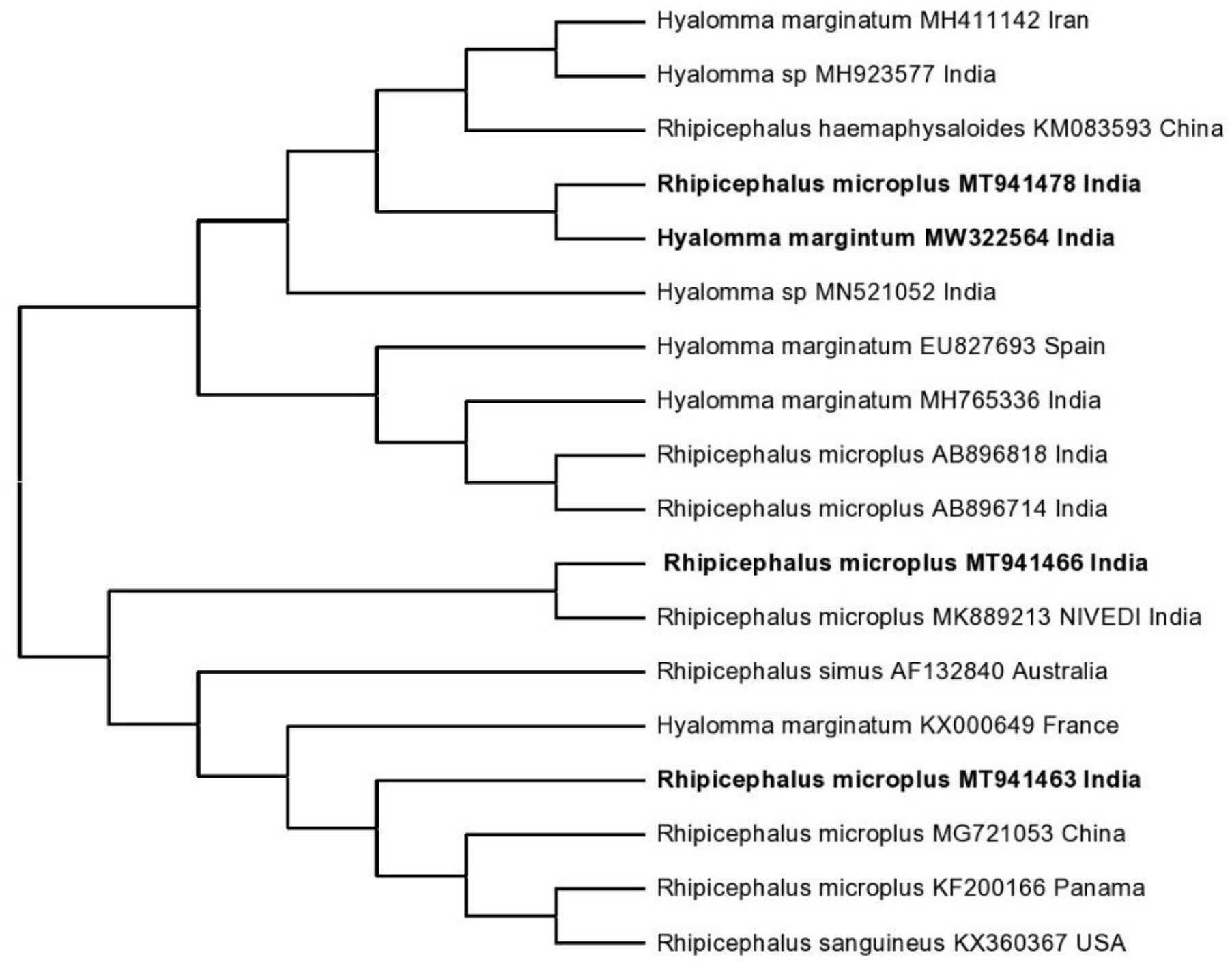

Figure 4

Molecular phylogenetic analysis of Rhipicephalus microplus and Hyalomma margintum isolated from the tick. COI genes were concatenated and subjected to analysis by the neighbor-joining method. 